\title{
Lesões Cutâneas Perianais em Doente com Infeção pelo VIH
}

\section{Perianal Cutaneous Lesions in a HIV Patient}

Ana Filipe Monteiro ${ }^{1}$, Margarida Ratoㅇ, João Aranha ${ }^{1}$, Ermelindo Tavares ${ }^{2}$

Autor Correspondente:

Ana Filipe Monteiro [anafilipemonteiro@gmail.com] Avenida Bernardo Santareno, 2005-177 Santarém, Portugal

PALAVRAS-CHAVE: Canal Anal; Hospedeiro Imunocomprometido; Infeção por VIH; Molusco Contagioso

KEYWORDS: Anal Canal; HIV Infections; Immunocompromised Host; Molluscum Contagiosum; Skin Diseases

Homem de 29 anos, referenciado por lesões cutâneas perianais com cinco meses de evolução. Medicado anteriormente com vários fármacos tópicos e sistémicos sem sucesso. Ex-toxicodependente de heroína e cocaína, homem que faz sexo com homens, portador de vírus da imunodeficiência adquirida $(\mathrm{VIH})$ e vírus da hepatite $\mathrm{C}(\mathrm{VHC})$ desde 1995; seguido em infeciologia e medicado com efavirenz, emtricitabina, tenofovir disoproxil, cotrimoxazol e metadona, que tomava irregularmente. A contagem dos linfócitos T CD4+ era de $56 / \mathrm{mm}^{3}$ e a carga viral (VIH) de 247 alg 2,39 cópias/mL. Ao exame objetivo apresentava conglomerado de lesões nodulares, pediculadas, rosadas e indolores, com diâmetro entre 5 e 15 mm na região perianal (Fig. 1). Colocaram-se como hipóteses de diagnóstico moluscos contagiosos, condilomas acuminados e condilomata lata. $\bigcirc$ exame histológico de biópsia incisional de uma das lesões confirmou a hipótese de molusco contagioso. Iniciou tratamento tópico com imiquimod creme 5\%, três aplicações semanais, durante 16 semanas. Aos três meses era evidente regressão quase total das lesões (Fig. 2). Completou tratamento às 16 semanas com resolução completa. Na consulta de seguimento aos 12 meses não apresentava recidiva.

molusco contagioso resulta da infeção pelo poxvírus que, raramente, acomete as mucosas. ${ }^{1}$ A doença é geralmente mais grave nos doentes com infeção pelo $\mathrm{VIH}$ e redução marcada dos linfócitos T CD4 $4^{+1-3}$ Clinicamente podem existir múltiplas lesões típicas (pápulas umbilicadas com menos de $1 \mathrm{~cm}$ ) e/ou atípicas (mais de $2 \mathrm{~cm}$, confluentes), colocando dificuldades no diagnóstico diferencial com condilomata lata (síflis secundária) e condilomas acuminados. ${ }^{4}$ Embora possa ocorrer resolução

1. Serviço de Dermatologia e Venereologia, Hospital de Santarém EPE, Santarém, Portugal.

2. Serviço de Dermatologia e Venereologia, Hospital Vila Franca de Xira, Vila Franca de Xira, Portugal.

Recebido: 05/03/2018 - Aceite: 29/03/2018 


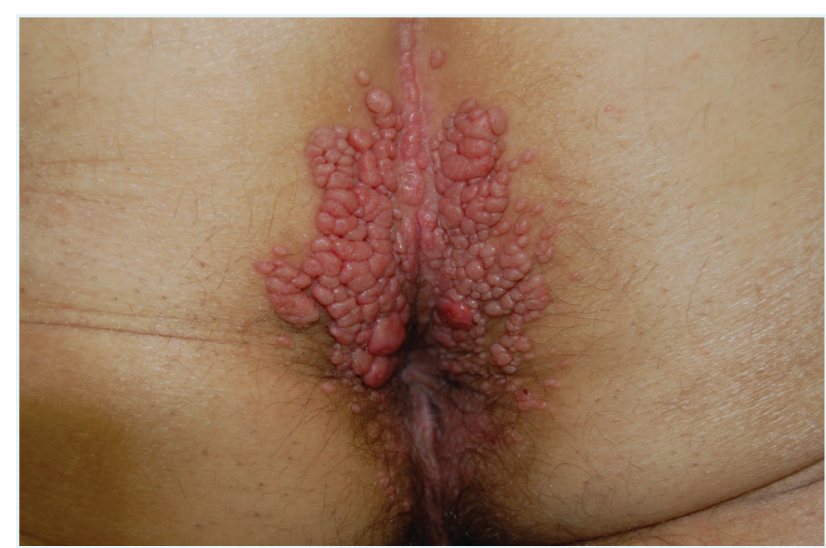

FIGURA 1. Conglomerado de lesões papulares e rosadas, com diâmetro variando entre 5 e 15 mm na região perianal.

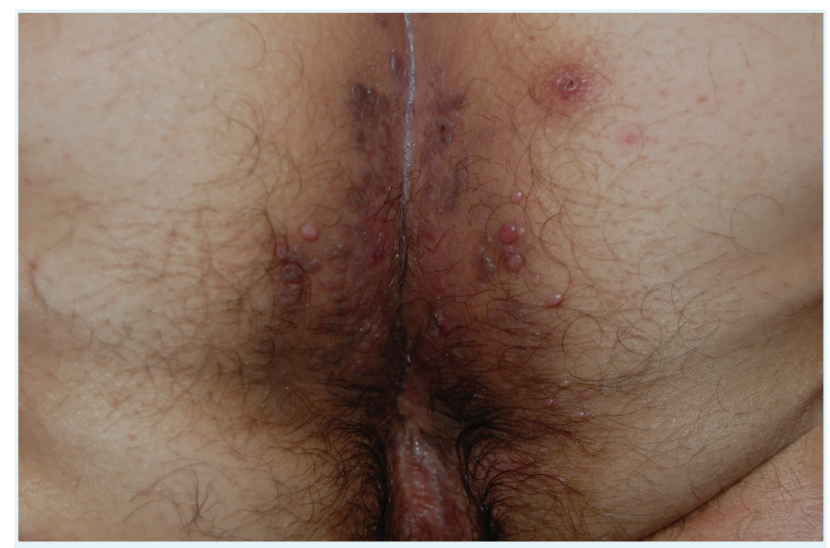

FIGURA 2. Regressão quase completa das lesões após três meses de tratamento.

espontânea com terapêutica antirretroviral, as lesões podem mostrar-se resistentes e recidivantes. ${ }^{4,5} \mathrm{O}$ imiquimod $5 \%$ creme é um imunomodulador e potenciador do sistema imune, que se mostrou ser uma alternativa "out of lable" segura., ${ }^{4,6}$ Outras opções terapêuticas convencionais na região genital passam pela utilização de crioterapia, curetagem e ácido tricloroacético.

CONFLITOS DE INTERESSE: Os autores declaram não ter qualquer conflito de interesse na realização do presente trabalho.

FONTES DE FINANCIAMENTO: Não houve qualquer fonte de financiamento na realização do presente trabalho.

CONFIDENCIALIDADE DOS DADOS: Os autores declaram ter seguido os protocolos da sua instituição acerca da publicação dos dados de doentes.

PROTEÇÃO DE PESSOAS E ANIMAIS: Os autores declaram que os procedimentos seguidos na elaboração do presente trabalho estão em conformidade com as normas das comissões de investigação clínica e de ética, bem como da declaração de Helsínquia e da Associação Médica Mundial.
CONFLICTS OF INTEREST: The authors declare that they have no conflicts of interest.

FINANCIAL SUPPORT: This work has not received any contribution, grant or scholarship.

CONFIDENTIALITY OF DATA: The authors declare that they have followed the protocols of their work center on the publication of data from patients.

PROTECTION OF HUMAN AND ANIMAL SUBJECTS: The authors declare that the procedures followed were in accordance with the regulations of the relevant clinical research ethics committee and with those of the Code of Ethics of the World Medical Association (Declaration of Helsinki).

\section{REFERÊNCIAS}

1. Buckley R, Smith K. Topical imiquimod therapy for chronic giant molluscum contagiosum in a patient with advanced human immunodeficiency virus 1 disease. Arch Dermatol. 1999;135:1167-9.

2. Pérez-Díaz CE, Botero-García CA, Rodríguez MC, Faccini- Martínez ÁA, Calixto O-J, Benítez F, et al. Giant Molluscum Contagiosum in an HIV positive patient. Int J Infect Dis. 2015;38:153-5.

3. Vora RV, Pilani AP, Kota RK. Extensive Giant Molluscum Contagiosum in a HIV Positive Patient. J Clin Diagn Res. 2015;9:12.

4. Choudhary S, Singh A, Gupta S, Koley S. Augmented effect of five percent imiquimod cream and antiretroviral therapy in resolution of giant molluscum contagiosum. Indian J Sex Transm Dis AIDS. 2008;29:102.

5. Strauss RM, Doyle EL, Mohsen AH, Green ST. Successful treatment of molluscum contagiosum with topical imiquimod in a severely immunocompromised HIV-positive patient. Int J STD AIDS. 2001;12:264-6.

6. Liota E, Smith KJ, Buckley R, Menon P, Skelton H. Imiquimod Therapy for Molluscum Contagiosum. J Cutan Med Surg. 2000;4:76-82. 